\title{
LA TEOLOGÍA ASIÁTICA DE LA LIBERACIÓN: UN CASO DE RECEPCIÓN, APROPIACIÓN Y REELABORACIÓN DE IDEAS
}

\author{
Asiatic Theology of liberation, a case study of recepction, \\ appropiation and elaboration of ideas
}

Eduardo Devés-Valdés*

\section{RESUMEN}

En el marco de un amplio proyecto que se ocupa del estudio de las ideas y particularmente de sus circulaciones, se elabora un modelo sobre el proceso de recepción-apropiación y reelaboración. Para ello se abordan las maneras en que fue "recepcionada" la teología de la liberación de América del Sur en Asia, cómo se produjo la apropiación de elementos y reelaboraron nuevas formulaciones. En particular se estudia la obra del teólogo esrilanqués Aloysius Pieris, y su propuesta de una teología asiática de la liberación.

Palabras clave: circulación de las ideas, teoría de la recepción, teología asiática de la liberación.

\begin{abstract}
Within the framework of a large project about the study of ideas and its circulations, the purpose of this paper is to build a model of reception, appropriation and elaboration. To achieve this goal, I discuss the process of reception of Latin-American theology of liberation in Asia, what was the appropriation of some aspects of its corpus and the elaboration of a new synthesis. In particular, I work about the SriLankan theologian Aloysius Pieris, and his "Asiatic theology of liberation".
\end{abstract}

Keywords: Circulation of ideas, reception theory, Asiatic liberation theology.

* Investigador del Instituto de Estudios Avanzados (IDEA) de la Universidad de Santiago de Chile. Santiago, Chile. Correo electrónico:edeves@usach.cl

Recibido el 23 de enero de 2017. Aceptado el 22 de mayo de 2017. 


\section{INTRODUCCIÓN}

El objetivo de este artículo es entender los modos de "recepción-apropiaciónreelaboración", de los sistemas eidéticos en un ecosistema intelectual diverso al que fueron elaborados, apuntando a la construcción de un modelo, para lo cual se estudiará el caso de la teología de la liberación en Asia. El trabajo se focaliza en los escritos del esrilanqués Aloysius Pieris y particularmente en su obra Hacia una teología asiática de la liberación (1991), en la cual muestra la recepción, apropiación y reelaboración crítica del discurso teológico latinoamericano.

La bibliografía acerca del tema de la recepción-reelaboración referido a la teología de la liberación en Asia es verdaderamente mínima. Apenas referencias marginales en trabajos que se refieren propiamente a la teología asiática y que dan cuenta de influencias, poco tematizadas, antecedentes vagos (Kim, 1998) siendo inversamente proporcional a la cantidad de publicaciones en torno a las diversas manifestaciones asiáticas emparentadas al liberacionismo latinoamericano; en Corea: Park 2011, Kim 1998, Lee 1988, Keel 1987, Hyun 1985, Park 1984, Ro s/f; en Filipinas: Aguilan 2011, Diaz, 2010, Garibay 1995, Fernández 1994; en la India: Rao 2011, Pattery 1994; en Taiwán: Song 1980.

Por otra parte, el tema de la recepción ha sido un asunto de vasta bibliografía en el marco de las teorías literarias Jauss (1987) e Iser (1993). El tema de la apropiación ha sido tratado en relación a las corrientes europeas de pensamiento en América del Sur, por Subercaseaux (1988) y al problema de las ideas fuera (o no) de lugar, por Schwarz (2000) y Palti (2014). Se formulan alternativas conceptuales y categoriales orientadas a entender específicamente los procedimientos de las comunidades intelectuales como productoras profesionales de nuevos sistemas eidéticos. En consecuencia, se intenta avanzar hacia un "modelo de re-elaboración", que pone énfasis en la creación de nuevos sistemas eidéticos, mucho más que en el modelo de recepción de obras literarias por parte de un público lector. Interesa en este caso específicamente lo que ocurre con las comunidades "productoras de pensamiento" en sentido fuerte, cosa que diferencia esta pregunta de la que se formulan quienes estudian la recepción de las obras literarias. En este sentido, la búsqueda no es tanto de una teoría de la recepción, cuanto una teoría de la reelaboración.

Ante esto se formulan 3 preguntas: 1. ¿Qué se recibió y/o seleccionó desde América del Sur? 2. ¿Qué operaciones se realizaron más simples o más complejas, en el proceso de apropiación y reelaboración? y; 3. ¿Qué nuevas formulaciones se alcanzaron recogiendo-criticando la Teoría de la Liberación en América del Sur?

La hipótesis es que los procesos de reelaboración que condujeron a una nueva síntesis, conocida como "teología asiática de la liberación" alcanzaron su formulación componiendo en lo fundamental tres elementos: la teología de la liberación de 
América del Sur (TLAS), en combinación con tendencias eidéticas presentes en el ecosistema intelectual de Sri Lanka en el cual Pieris trabajaba, en particular la relevancia atribuida a la cultura y el pensamiento budista, y un elemento muy propio de la propia trayectoria de Pieris, su formación en la teológica occidental que más reconocida en aquel momento, asumiendo que la recepción y apropiación de ideas se realizó a partir de las obras de la TLAS traducidas al inglés (dado que los autores asiáticos, en general, no leían español ni portugués, lenguas en que fue elaborada) y a través de contactos en redes como la Asociación Ecuménica de Teólogos del Tercer Mundo, EATWOT, sigla en inglés (ver Devés 2016).

Dicho lo anterior, debe tenerse en cuenta que en este trabajo no se discute si la TLAS fue bien o mal leída, ni tampoco si los elementos tomados de esta, en las reelaboraciones realizadas por la teología asiática, fueron aquellos que los autores latinoamericanos consideraron claves. Por otra parte, este trabajo no puede exponer el pensamiento liberacionista latinoamericano, que se entenderá conocido y quien desee profundizar podrá ir a la bibliografía citada.

\section{MOMENTOS Y OPERACIONES EN EL PROCESO DE RECEPCIÓN- APROPIACIÓN-REELABORACIÓN DE SISTEMAS EIDÉTICOS}

Se entiende por momento cada uno de los pasos en el proceso de recepciónapropiación-reelaboración de un sistema eidético, producido fuera del ecosistema intelectual en estudio. Se denominan "operaciones" los procedimientos por medio de los cuales: se va realizando el proceso de recepción-selección, aproximación, filtración, sea externo o interno al ecosistema receptor; se va produciendo la apropiación a través de fórmulas, sean más simples, ingenuas o miméticas, o en fórmulas más complejas, maduras o críticas, elaborando nuevos conceptos; se va produciendo la cristalización de un nuevo sistema eidético, cuestionando el introducido, por sus limitaciones, elaborando categorías articuladoras y también creando una nueva denominación. Las operaciones sugeridas no son todas necesarias y pueden realizarse de maneras algo diferentes. Es decir existen específicos modelos de recepción-apropiación-reelaboración. Se entiende por "modelo de recepción-apropiación-reelaboración" la particular combinación de procedimientos a través de los cuales un pensamiento es asumido en un medioambiente intelectual diferente de aquel en el cual se originó, que se juega en las distintas vías de implementación de los cinco momentos y sus respectivas operaciones. Los modelos se dividen principalmente en "completos" e "incompletos", siendo los segundos los más frecuentes, es decir aquellos en que se cumplen solo las primeras etapas, las menos creativas, y no las últimas del proceso. 
Primer momento: Recepción a partir del filtrado externo, previo, a la recepción por parte del ecosistema en estudio. Aquello que fue disponibilizado por agentes exteriores al ecosistema, aquello que había sido editado, traducido, enviado, distribuido, circulando en las redes.

Operación de lectura de obras previamente traducidas donde se expresa el sistema eidético en cuestión.

Operación de recepción de un canon establecido en el ecosistema emisor, donde se establecen las obras claves del sistema eidético, las que serán eventualmente republicadas, antologadas y traducidas.

Operación de incorporación a redes establecidas que, inicialmente al menos, no dependen del ecosistema intelectual receptor.

Operación de incorporación a la institucionalidad y programas de formación a los cuales pueden concurrir personas del ecosistema receptor.

Segundo momento: Recepción por filtrado interno y proactivo para la recepción-selección-aproximación de acuerdo a criterios provenientes del ecosistema receptor. Este es el primer nivel de apropiación con un "horizonte de experiencias-expectativas".

Operación de lectura selectiva de aquello que es más aprovechable, de acuerdo al horizonte de expectativas, a partir de sistemas eidéticos ya instalados en el ecosistema.

Operación de búsqueda de contactos, traducción de otras obras, creación de contactos y hasta aprendizaje de lenguas a partir de la iniciativa del receptor.

Tercer momento: De elaboración simple, de aprovechamiento de las ideas de manera más inmediata y sin que medie creación conceptual.

Operación de lectura del sistema eidético recepcionado a partir de las categorías pre-existentes en el ecosistema de recepción, partiendo por lo más amigable y familiar.

Operación de reinterpretar la realidad y la historia de la propia sociedad y más allá con el sistema eidético recepcionado.

Operación de asociar el nuevo sistema eidético a las disyuntivas del ecosistema intelectual.

Cuarto momento: De reelaboración compleja y creación conceptual.

Operación: De detección en la realidad de problemas susceptibles de ser interpretados (privilegiadamente) con el sistema eidético recepcionado, ello en tensión con el tercer momento, de recepción ingenua, podía parecer que toda la realidad era interpretable con el SE importado.

Operación de creación de conceptos inspirados en el sistema eidético recepcionado, para entender fenómenos específicos que no estaban en la versión originaria-importada, porque no era relevantes para el ecosistema en el cual fue plasmado. 
Operación de cruzamiento es decir, de encuentro y articulación de nociones de diversas procedencias, sean ancestrales del propio ecosistema y/o provenientes de otras importaciones recientes, con elementos del sistema eidético en proceso.

Quinto momento: De bautizo, articulación, crítica y agenda, donde se apunta a una nueva denominación, que se alcanza en la articulación, fusión o cruzamiento entre componentes del sistema eidético arribado (y eventualmente otros foráneos) y uno o más de los presentes en el ecosistema de recepción, en la crítica al sistema eidético arribado como insuficiente y en la formulación de una agenda de trabajo coherente con esta novedad.

Operación de denominación de bautizo del nuevo sistema eidético.

Operación de crítica y detección de insuficiencias y limitaciones del sistema eidético recepcionado para entender la realidad de quienes recepcionan, en ruptura explícita con la ingenuidad primera que lo adoptaba como paquete y panacea.

Operación de elaboración de categorías de articulación o de síntesis que permitan el encuentro, fusión o cruzamiento entre elementos de sistemas eidéticos diversos.

Operación de formulación de una agenda del nuevo sistema eidético como expresión de su novedad.

\section{EL CASO: APLICACIÓN A LAS RECEPCIONES-APROPIACIONES- REELABORACIONES DE LA TEOLOGÍA DE LA LIBERACIÓN EN ASIA}

Se procederá a mostrar estas operaciones a través de la tendencia eidética procedente de América del Sur que más efecto internacional ha tenido: la teología de la liberación. Esta se ha proyectado hacia numerosos ecosistemas intelectuales de África, Asia y del Pacífico como también del centro, permitiendo recepciones, apropiaciones y reelaboraciones (ver Devés 2014). Se trabajará a partir del teólogo esrilanqués Aloysius Pieris, prioritariamente, pero ello se complementará con otros casos de la región, que hayan realizado estas mismas operaciones y que sirvan para ilustrar los procedimientos que se han formulado más arriba . El esrilanqués es doblemente interesante. Por una parte lleva a cabo un proceso de recepciónapropiación-reelaboración y por otro, se plantea expresamente la necesidad de elaborar un sistema eidético original, ofreciendo él mismo varios criterios para esto. Estos criterios se irán poniendo de manifiesto a través de la exposición. Ahora bien, en cada operación podrían haberse agregado otras manifestaciones en que se expresaran los aportes de Pieris. 


\section{Recepción a partir del filtrado externo}

Pueden señalarse dos puntos: los teólogos asiáticos de acuerdo a lo que se observa en sus citaciones y referencias, salvo muy pocos, no conocen el español o el portugués, por lo cual el acceso a la TLAS es a partir de las obras traducidas al inglés, y ello en gran parte es lo publicado por Maryknoll-Orbis, y a través de diálogos académicos en espacios internacionales, entre otros la red EATWOT, de la cual participó Pieris, como él mismo lo expresa al darnos la procedencia de los trabajos reunidos en el volumen que se estudia aquí.

\section{Recepción por filtrado interno}

Operación: De selección de aquello que es más aprovechable. Pieris lee más bien autores católicos como él, que protestantes. Dentro de los autores más citados por Pieris en la obra estudiada se encuentran: Gustavo Gutiérrez, J. P. Miranda, J. L. Segundo, E. Dussel, J. C. Scannone, Jon Sobrino, Virginia Fabella, S. Torres. Protestantes como R. Alves o J. Míguez-Bonino, no son referidos. Por otra parte, son constantes sus críticas a los teólogos protestantes europeos, particularmente de la "hermenéutica bíblica", como de la teología dialéctica (Barth).

Operación: De búsqueda, traducción, contactos. Lo más manifiesto en Pieris como búsqueda de posicionamiento propio consiste en haber convocado la tercera reunión de la EATWOT en Sri Lanka en 1979. Esta decisión muestra un afán por alcanzar algún protagonismo en estas redes, teniendo así la capacidad de instalar sus temas y criterios.

\section{Apropiación simple, poco elaborada}

Una de las cuestiones clave entre quienes se inspiran en sistemas eidéticos importados es que asumen que representan algo así como "revoluciones copernicanas" o radicales "rupturas epistemológicas", respecto a lo que se ha pensado antes y que dicho sistema eidético traería consecuencias muy favorables para la sociedad de la cual participa el intelectual importador, o al menos este es el discurso de estilo. Aloysius Pieris, no es ningún ingenuo, no es un jovencito que piensa que su descubrimiento transformará la realidad social de Asia. Sin embargo ve en la TLAS cuestiones de tal modo innovadoras y positivas que permiten ubicarlo entre quienes asumen "revoluciones copernicanas". Según su manera de conceptualizar las cosas, afirma que se ha dicho que la teología clásica de occidente, que "a partir del siglo XIX ha pasado por el molino de la renovación, ha 'abierto brecha' a mediados de este siglo, culminando en la teología moderna con su apertura al 'mundo"', según Mark Schoof (1970), continúa Pieris: 
los principales centros de esta renovación se encuentran en los países de habla francesa y alemana porque fue allí donde 'los teólogos contaron con la necesaria tradición científica y la suficiente energía creativa’. Una de las principales fuentes de inspiración para la renovación de la teología católica europea se encuentra más atrás, en la Alemania protestante (1991: 64).

Sin embargo, escribe más adelante, ello no es así, y Schoof magnifica cambios muy parciales. Argumenta Pieris que "un asiático que se sitúa a distancia y contempla las cosas con ojos críticos descubre una imagen muy distinta”, pues

el real abrir brecha en la teología occidental vino con la crítica que Latinoamérica hizo de aquella misma 'tradición científica' a la que se refiere Schoof con orgullo. La apertura al mundo que consiguieron los teólogos europeos hasta los años sesenta en su diálogo con las filosofías contemporáneas es sólo una ligera reforma comparada con lo que los latinoamericanos consiguieron a partir de los años sesenta (1991: 64).

Según Pieris, los latinoamericanos sí "realizaron un cambio completo de método", haciendo "con la teología europea algo semejante a lo que hizo Feuerbach con la dialéctica de Hegel”. En otras palabras, "pusieron a la teología de nuevo sobre sus pies, la hicieron tocar tierra en la teopraxis. Lo que antes giraba en torno a una órbita kantiana se le obligó a girar sobre un eje marxista” (1991: 64-65).

Operación: Lectura por lo más amigable o familiar. En el caso de la teología asiática esto se expresa de diversas maneras. Una forma es leer la TLAS “acercando" lo nuevo a lo que ya se posee, como por ejemplo acercándola a las categorías de los teólogos más influyentes en el ecosistema receptor. Es el caso de Pieris cuando parece querer entroncarse en una trayectoria india de teólogos como Amaladoss y Pannikar, con su insistencia en un cristianismo hindú (1991: 165).

Otra forma, es articulando la recepción de la TLAS a la historia social y del pensamiento social y socialista de Asia, ello sin la recuperación de categorías marxistas como instrumento de análisis. En este marco deben entenderse las frecuentes alusiones a pensadores políticos M. Gandhi, Mao, Ho Chi-min, U-Nu, apuntando a lo que Pieris llama "zona común de interés en la que parecen convergir dos filosofías tan distintas".

Hablamos del artículo básico de fe que tanto Gandhi como Mao expusieron a sus seguidores: la «mística asiática», cuya soberanía es inviolable, reside en el corazón de los campesinos; la esperanza de Asia está en la población rural; la autodeterminación de campesinos y trabajadores es, en sí misma, la liberación de Asia (1991: 40). 
Operación: Interpretar la realidad con el nuevo sistema eidético: La clave de esta nueva interpretación, se encuentra en la relectura que hace Pieris de la realidad asiática y mundial. Asia es asumida por él como "el continente de los pobres" y el tercer mundo, entendido como "como perspectiva teológica" conduce a que

la expresión Tercer Mundo es un neologismo teológico por el pueblo de Dios. Representa a los hijos hambrientos de Jacob de todo tiempo y lugar que van en busca de pan a un país rico sólo para convertirse en esclavos. Dicho de otro modo, el «Tercer Mundo» es algo que ocurre siempre y donde la dependencia socioeconómica en términos de raza, clase, o sexo da lugar a una esclavitud política o cultural que, a su vez sirve de fermento a un nuevo pueblo (1991: 97).

Operación: Asociar el nuevo sistema eidético a las disyuntivas del ecosistema intelectual. De las operaciones conceptualizadas esta es la única que parece no advertirse en Pieris, quizás porque en la obra analizada no discute con otras personas o posiciones de su ecosistema intelectual, sino con posiciones externas o sin mención de lugares específicos.

\section{Apropiación más creativa o elaborada y de creación conceptual}

Así como asumió que había una especie de revolución copernicana, no dejó de señalar críticas al quehacer teológico sudamericano y ello precisamente es lo que le hace mostrar reservas e intentar innovaciones conducentes precisamente a una teología asiática de la liberación. Si asume que la TLAS constituye una teología

radicalmente renovada por los desafíos del tercer mundo" y “que es más conveniente y apropiada a Asia que la teología clásica”, no deja por ello de agregar que "para nosotros, asiáticos, la teología de la liberación es totalmente occidental”. En este sentido conviven esa dimensión occidental y, por tanto, limitada, con un "nuevo método teológico, ciertamente el método correcto para hacer teología (1991: 65).

Toma entonces de Jon Sobrino (1975) lo que llama aquellas características de esta metodología "que son más aplicables y pertinentes para nosotros en Asia" (1991: 65). Según interpreta a Sobrino, y resumiendo:

La primera característica es que el intento kantiano de 'liberar la razón de la autoridad' preparó el camino a una preocupación teológica por armonizar 'fe y razón', mientras que el intento marxista por 'liberar la realidad de la opresión' no recibió atención teológica en Europa, hasta que los latinoamericanos decidieron emprender esta tarea" (1991: 65). "La segunda característica, muy importante para los asiáticos, es la primacía de la praxis sobre la teoría. Conocemos a Cristo Verdad 
si seguimos a Cristo Camino" (1991: 66). "En tercer lugar, este Camino es el camino de la cruz" (119: 66). "En cuarto lugar, vemos que esto no es una 'teología del desarrollo' que justificaría y perpetuaría los valores de una cultura 'adquisitiva' sino una 'teología de la liberación' que demanda un ascetismo de renuncia y una pobreza voluntaria, que desprecia la codicia e inculca una participación dinámica en su lucha por una humanidad completa" (1991: 66). "Finalmente, el encuentro de Dios y el hombre, es decir, la relación entre gracia y libertad, se presenta como una obligación del hombre de hacer uso de todas sus potencialidades humanas para anticipar el reino de Dios" (1991: 66), (y ello) "explica la opción política de los teólogos de la liberación por el socialismo [...] partiendo del presupuesto de que nadie está liberado hasta que todos lo estén (1991: 67).

Pero este método, afirma, debe completarse con los aportes o referencias al contexto asiático. Por ello "nuestra crítica sobre la forma de operar" de ciertos sistemas eidéticos en Asia ha situado claramente a ambas teologías, la europea y la TLAS,

en el contexto de la religiosidad oriental. Por tanto, nuestra tarea consiste en completar el método latinoamericano con una crítica asiática de la teología clásica (1991: 67).

Operación: Detección en la realidad de problemas susceptibles de ser interpretados. Es clave en esta reflexión de Pieris la manera que él concibe Asia, pues ello le permitirá afincar una reflexión en busca de especificidad. Aprovecha para ello una reunión de la EATWOT (1991: 45-46). Para ello se focaliza en dos dimensiones la "característica tercermundista de nuestro continente" y lo que denomina "su peculiar carácter asiático" que son "dos puntos de referencia que nunca debemos perder de vista. Puesto en términos más reales, el denominador común de Asia y del resto del tercer mundo es su abrumadora pobreza; el carácter específico que define a Asia dentro de los demás países pobres es su polifacética religiosidad" (1991: 45).

Operación: Elaboración de nociones o conceptos nuevos. Pieris reelabora la noción de los pobres que se encontraba en la TLAS, radicalizándolo, por un lado y otorgándole parcialmente nuevas significaciones. Plantea que Asia es el continente con más pobres, es el continente de los pobres, marcando como trazos de lo asiático su abrumadora pobreza y su religiosidad. Esto le permite pensar la especificidad asiática como similar y diferente de América del Sur. Retomando y recreando: "en Asia, donde existe en nuestro ethos cultural un 'punto todavía no descubierto' en el cual pobreza y religiosidad parecen fundirse en orden a crear el carácter asiático de este continente" (1991: 46). En tal sentido es necesario "tomar conciencia de que la pobreza en Asia no puede reducirse a categorías puramente 'económicas'. Ambos están entrelazados cultural y económicamente constituyendo la compleja realidad sociopolítica que es Asia” (1991: 45). 
Correlativa a lo anterior, es la tarea de reelaboración del concepto liberación, entendido a la manera asiática, en el marco de la cultura y la trayectoria asiáticas y por tanto en relación a cuestiones identitarias, pertinentes a la realidad, y liberadoras en el marco de la cultura esrilanquesa y, más ampliamente, asiática, es decir, con paradigma asiático de liberación. Plantea que la Biblia ya "nos ha dejado probado" que "la experiencia religiosa (la fe-compromiso, la espiritualidad de la lucha) que caracterizó a pueblos colonizados y explotados: y eso es un paradigma excelente de un Dios-encuentro (es decir, liberación) para los pobres de Asia” (1991: 188). Otra aproximación posible para Pieris, tiene que pensarse en relación al tema del socialismo budista, en la medida que, "desde los ańos cincuenta, Asia sureste ha producido ya tres ramas diferentes de 'Socialismo Budista' (1991: 39) .

Operación: De cruzamiento. Para Pieris, en el caso de la teología asiática, debe asumirse el cruzamiento de la trayectoria teológica occidental, y algunas de sus categorías más importantes, con la trayectoria asiática y principalmente budista. Retomando lo que se mencionaba en el acápite anterior, incluso el paradigma "liberación" debe modificarse. Dada precisamente la importancia del budismo, es que "no puede construirse una teología de la liberación en Asia sin tener en cuenta el budismo asiático" (1991: 51). La clave de esta afirmación reside en que existe una soteriología asiática no reductible al cristianismo occidental, en un continente que rehúsa convertirse al cristianismo. Esto tiene aplicación especialmente en Asia, "donde existe en nuestro ethos cultural un "punto todavía un no descubierto" en el cual pobreza y religiosidad parecen fundirse en orden a crear el carácter asiático de este continente". Expresión de ello es que "después de cuatro siglos de presencia misionera, los cristianos son numérica y cualitativamente una minoría insignificante" y "Asia, como lo indican claramente las circunstancias, siempre será un continente no-cristiano" (1991: 46). Sin embargo, argumenta, "esta limitación es a la vez la mayor potencialidad que posee la Iglesia de Asia para crear una teología del tercer mundo que será radicalmente diferente de las teologías sudamericana y africana” (1991: 52). Para esto hay que destacar otras fórmulas soteriológicas. Para que ello sea posible y "antes de nada, debemos volver a captar la imagen del budismo institucional con sus dimensiones cósmica y metacósmica de la experiencia religiosa. A la esfera cósmica deben ser relegados: a) Todas las actividades sociopolíticas, b) El proceso tecnológico y científico. A la esfera metacósmica pertenece todo lo que está ordenado a la liberación interior del hombre" (1991: 52). Ante esto, pretende "volver a enfocar la cuestión" y plantea que "en todas las soteriologías no-bíblicas de Asia, religión y filosofía se mezclan de forma inseparable. La filosofía es una visión religiosa (del mundo) y la religión es una filosofía vivida" (1991: 68). Es el caso del budismo, en este "la meta de la vida es el arte de vivirla. La perfección a conseguir es el estilo de conseguir la perfección. La consecuencia clara que se deduce es que el método asiático de hacer teología es en sí mismo teología asiática. La teopraxis es ya la formulación 
de una teología” (1991: 68). Y en este marco, lo formula más radicalmente como un "perderse a sí mismo en la participación total".

¿Cuál es, pues, el lugar de esta praxis? Ciertamente no es la "vida cristiana vivida dentro de la Iglesia en presencia de los no-cristianos"; es más bien la "experiencia de Dios del pueblo de Dios que vive más allá de la Iglesia" y entre el que la Iglesia es llamada a perderse a sí misma en total participación. Es decir, la teología en Asia es el apocalipsis cristiano de las experiencias no-cristianas de liberación (1991: 71).

\section{Cristalización de un nuevo sistema eidético}

Operación: Denominación. Esto es lo que llama una "teología asiática de la liberación”, que es la fórmula que da título al libro, o una "teología de la liberación en Asia” (“Asian Theology of Liberation”, “Theology of liberatión in Asia”).

Operación: Crítica del sistema eidético recepcionado. La mayor muestra de la madurez intelectual de Pieris y de su intención de elaborar un sistema eidético que incorpore y supere la TLAS, es la crítica a la que la somete, a pesar de considerarla un inmenso aporte. La reelaboración pasa por la valorización de la TLAS, pues "aunque totalmente occidental" ha sido "tan radicalmente renovada por los desafíos del Tercer Mundo que es más conveniente y apropiada a Asia que la teología clásica” (1991: 65) y su novedad reside principalmente en que se trata de un "nuevo método teológico, ciertamente el método correcto para hacer teología” (1991: 65). Pero por este carácter "totalmente occidental" debe ser criticada o puesta en sus justos términos.

Pieris cuestiona la TLAS, y otras teologías contemporáneas, como "occidentales-occidentalistas" y por ello incapaces de comprender-expresar la especificidad asiática. Esto deriva, entre otras cosas, de la aceptación acrítica por parte de estas de las nociones de Marx, Freud y Karl Barth, europeos de su tiempo, incapaces de entender la realidad asiática, especialmente en aquello de malentender el fenómeno religioso asiático. Esta limitación de la TLAS hace que su propio "lenguaje latino y marxista no permite que la identidad étnica de las minorías raciales se refleje en su teología. Esto ocurre con los amerindios, los negros, y los asiáticos, casi la quinta parte de la población sudamericana, son también una mayoría absoluta en algunas provincias" (1991: 105) haciéndola por ello mismo limitada también para la propia América del Sur.

Correlativo con lo anterior, es que los teólogos latinoamericanos de la liberación se muestran si no negativos (Miranda, Sobrino) sí ambiguos (Gutiérrez, Segundo) con respecto al papel de la religión en el proceso de la liberación (ver Sánchez-Rivera 1991:14). Puede señalarse que para Pieris, "paradójicamente, los liberacionistas están emparentados con los teólogos "clásicos" europeos en su afán de presentar a Cristo como un Cristo contra las religiones" y que ello se debe a la sumatoria de la 
influencia del marxismo y de la hermenéutica bíblica (1991: 77) y esta concepción sería profundamente perjudicial, pues haría imposible la liberación, porque en Asia, al menos, "la liberación verdadera no es posible si el pueblo no está motivado "religiosamente" (1991: 124). Este occidentalismo de la TLAS, que califica como "la única teología válida hoy para el tercer mundo", le impide a esa misma teología una comprensión profunda del ideal monástico tan importante en Asia. El desconcierto marxista frente a la religiosidad indestructible de Asia puede reaparecer en una teopraxis asiática demasiado subordinada al modelo latinoamericano (1991: 62).

Operación: Elaboración de categorías de articulación o de síntesis. Pieris elabora la noción "zona común de interés", una especie de "mínimo común" o de "punto de encuentro", donde pueden dialogar pensamientos diferentes. Explicita esta noción al referirse en lenguaje teológico al "artículo básico de fe" este que tanto "Gandhi como Mao expusieron a sus seguidores: la "mística asiática», cuya soberanía es inviolable, reside en el corazón de los campesinos” (1991: 40). Otra manera de formular esto mismo es a partir del caso de una zona común de los indígena asiático, que tanto el budismo como el socialismo son indígenas de Asia y que la zona común en la que se encuentran ha de ser, igual y auténticamente asiática, de modo que gnósticos y budistas "han encontrado su punto de confluencia en el campesinado asiático que es el que encarna, en verdad, el espíritu de Asia" (1991: 39). Explica esta referencia, señalando que su referencia al budismo "no es accidental", por el contrario (ver Premawardhana, 2011).

es muy razonable que me centre en una de las grandes religiones si hemos de enfocar en profundidad el problema de la religiosidad asiática. He escogido el budismo no sólo porque me es más familiar, sino sobre todo porque es la única religión panasiática en cuanto a integración cultural, fuerza numérica, extensión geográfica y madurez política," (siendo además políticamente) "la religión más elástica y resistente de Asia y tiene un papel muy importante que jugar en el desarrollo y liberación de Asia, pues ha adquirido una rica experiencia tanto del colonialismo occidental como del marxismo (1991: 50).

Operación: Agenda del nuevo sistema eidético. La nueva denominación va acompañada de una agenda de trabajo (explicitada o no) que contribuye a perfilar mejor el carácter de la nueva propuesta. De este modo, Pieris plantea que la condición básica para elaborar una teología asiática de la liberación consiste en la necesaria "asiatización" de la teología. La teología puede seguir, en cierta forma, el proceso del marxismo, porque este se "asiatizó" muy tempranamente. Porque "el marxismo no es ya, en Asia, una ideología "importada”, aunque el marxismo sea la única "religión” nacida en el oeste, está ya más asiatizado que la religión cristiana, que es asiática de origen y occidental por adopción (1991: 38). 
Esto querría decir que la teología asiática de la liberación es aquella que logra "insertarse en el ethos asiático" (1991: 87), que ha logrado el marxismo. ¿Cómo lo hizo el marxismo? Si debe continuarse con este paralelo, los procesos de "asiatización" del marxismo consisten, por una parte, en asumir los dialectos vernáculos, porque este "empezó a estudiar a fondo, a poner por escrito, a discutir, e incluso a desarrollarse en dialectos vernáculos, cuando todavía la teología cristiana se balbuceaba en latín en los seminarios de Asia" (1991: 38); por otra, en asumir el socialismo religioso de Asia como propuesta, como alternativa, pues los "grandes líderes políticos de Asia vieron en el socialismo religioso de Asia un gran antídoto político y social contra el capitalismo, el consumismo y, por supuesto, el feudalismo que todavía subsiste" (1991: 87); y también, en asumir la significación de las religiones asiáticas, por ejemplo, cuando "Mao decidió no oponerse al confucianismo" (1991: 38).

Y complementariamente, en la línea de inspirarse en la cultura asiática y en el socialismo asiático, como parte de esta, Pieris releva que, puesto que "la lucha entre gracia y pecado, entre Dios y Mammón, está siempre presente en Asia”, debe entonces considerarse "la adopción del socialismo rural (como) un imperativo religioso y una opción política”. Y la reivindicación de este socialismo rural asiático debe entenderse articulado a la "revolución eclesiológica que tan vivamente esperamos, como preludio a la inculturización e indigenización, no es otra que la respuesta evangélica a las promesas que el socialismo religioso de Asia ofrece a nuestra Iglesias locales de hoy" (1991: 87). En su caso, dice presuponer "que el instinto religioso puede definirse como un impulso revolucionario, el impulso psico-social a crear una humanidad nueva. La búsqueda religiosa es, en otras palabras, el deseo irresistible de humanizar lo que solo ha sido hominizado" (1991: 125-126). Esto debería expresarse también al asumir el asunto de las comunidades de base apostólicas, "por eso sugerimos que si el punto de inserción de la Iglesia local en el ethos asiático es la multiplicación de comunidades de base, entonces Asia ofrece motivos estimulantes para crearlas y presenta su propia matriz indígena donde gestarlas" (1991: 87).

\section{CONCLUSIONES}

En síntesis, se ha desarrollado un "modelo" para entender el proceso recepción-apropiación-reelaboración entendiéndolo en cinco momentos, con las respectivas operaciones que los realizan o explicitan. Luego este modelo ha sido satisfecho con el caso de Aloysius Pieris, mostrando los procedimientos y operaciones a través de los cuales un sistema eidético es re-trabajado en un ecosistema intelectual diverso a aquel en el cual se originó. Ello nos permite acceder a un modelo específico de recepción-apropiación-reelaboración, que puede 
caracterizarse de "completo", por una parte, porque satisface todos los momentos, aunque no claramente todas las operaciones formuladas.

Respecto al primer momento. En otro trabajo (Devés, 2016) se mostró cómo los teólogos anglófonos asiáticos recibieron la TLAS preferentemente desde dos canales: las publicaciones de Orbis Books y la red EATWOT. En la primera Pieris además publicó su propia obra, en la segunda participó y organizó el tercer encuentro.

Sobre el segundo momento. A partir desde lo recibido, desde lo posible, su criterio de selección operó sobre aquellos elementos más pertinentes. La cuestión del marxismo como instrumento de análisis, fue poco y nada recepcionada, y la crítica de la religión como opio y la idea del "Cristo contra las religiones", francamente desechadas. El énfasis en cuestiones sociales fue ampliamente acogido y Pieris insistió varias veces en la fórmula del socialismo asiático.

El tercero, un proceso más simple de apropiación, por el cual se asumió que la TLAS representaba una revolución teológica que permitiría hacer teología nueva desde el tercer mundo.

El cuarto momento, un trabajo más complejo de elaboración y reelaboración conceptual. Aquí se ubica su reinterpretación de la pobreza y de la liberación entendidas a la manera asiática, en el marco de la cultura y la trayectoria asiáticas.

El quinto, Pieris reformula la teología de la liberación a la manera asiática, criticando la TLAS, tratando de mostrar sus limitaciones para pensar la realidad asiática y para el avance de la liberación de su pueblo, en su concepto, y trabajando la noción de "zona común" sobre la base de la cual elaboraría lo más fuerte de su propuesta, argumentando que la liberación de Asia debe ser coherente con las trayectorias que definen asiáticamente lo que significa liberación.

La teología de la liberación fue imaginada desde América del Sur mucho más como teología de-para los pobres que desde nuestra identidad. En Asia fue leída como una teología "contextual", particularmente en Corea del Sur, pero también en Sri Lanka, India, Taiwán y hasta Filipinas, aunque menos allí. Contextual quiere decir muy asociada a la situación en que aparece, y cada teólogo/a entiende lo contextual poniendo sus propios énfasis, así Pieris asumió el budismo como cuestión clave.

Pero, la TLAS tuvo un efecto más amplio: otorgó seguridad a los quehaceres teológicos de las regiones periféricas. Si en algún lugar se podía desarrollar una teología propia, con énfasis diferentes a los centros, también era posible hacerlo en otros lugares del mundo. De este modo, tuvo otros efectos: uno general, la apertura a trayectorias teológicas no elaboradas en el centro, otros específicos: contribuyó a la introducción del concepto liberación de los pobres y los oprimidos como parte del discurso teológico de Asia y África. 


\section{REFERENCIAS}

Aguilan, Victor. "Encountering Jesus in the midst of struggle. A Christology of Struggle”, 2011. Disponible en http://www.academia.edu/7371839/ Christology_of_struggle

Alves, Rubem. Towards a Theology of Liberation: An Exploration of the Encounter Between the Languages of Humanistic Messianism and Messianic Humanism, 1968. (Ph.D. diss.). Princeton: Princeton Theological Seminary. Publicado como Alves, Rubem (1969). A Theology of Human Hope. Washington: Corpus.

Bretzke, James T. "A Pentecost Parable: Minjung Theology as an Expression of the Holy Spirit in Korea "Cracking the Code: Minjung Theology as an Expression of he Holy Spirit in Korea”. Pacifica 10, 1997.

Devés, Eduardo. "La circulación de las ideas, una conceptualización: el caso de la teología latinoamericana en Corea del Sur", Revista Estudios Avanzados, Santiago de Chile, julio, 2016.

Devés, Eduardo. Pensamiento Periférico Asia - Africa - América Latina - Eurasia y algo más. Una tesis interpretativa global. Buenos Aires: CLACSO, 2014.

Devés, Eduardo. El pensamiento Latinoamericano en el siglo XX: Desde la CEPAL al neoliberalismo 1950-1990. Buenos Aires - Santiago de Chile: BiblosCentro Barros Arana, 2003.

Diaz, Johnathan Blas. "Forward." Towards a Theology of the Chamoru: Struggle and Liberation in Oceania. Quezon City, Philippines: Claretian Publications, 2010.

Dussel, Enrique. Teología da Libertação. Um panorama de seu desenvolvimento, Vozes: Petrópolis, 1999.

Fabella, Virginia (ed.). Asia's Struggles for Full Humanity: Towards a Relevant Theology. Orbis Books, Nueva York, 1980.

Fernández, Eleazar. Toward a Theology of Struggle. Maryknoll, N.Y.: Orbis Books, 1994. 
Garibay, Emmanuel. "Christology in the Philippine Context," NCCP Newsmagazine [April-June, 1995).

Go, Julian. "Colonial reception and cultural reproduction: Filipino elites and United States tutelary rule". Journal of Historical Sociology, 12/4 (1999).

Gutiérrez, Gustavo. A Theology of Liberation. Maryknoll. New York: Orbis Books, 1973.

Gutiérrez, Gustavo. A Theology of Liberation. Londres SCM Press, 1974. Iser, Wolfgang. "La interacción texto- lector". En busca del texto, teoría de la recepción literaria, Dietrich Rall (Comp.). México: UNAM, 1993.

Jauss, Hans Robert. "El lector como instancia de una nueva historia de la literatura", Estética de la recepción. Madrid: Arco libros, 1987.

Keel, Hee-Sung. "Korean Theology: Past and Present", Revista Inter-Religio, 12 (1987).

Kim, Eunsoo. "Minjung Theology in Korea A Critique from a Reformed Theological Perspective", Japan Christian Review, 64 (1998).

Kwang-sun Suh, David. "Minjung and theology in Korea", Minjung Theology. People as the subject of history, CCA-CTC, Singapur, 1981.

Lee, JungYoung. "Minjung Theology: A Critical Introduction," en Jung Young Lee, ed., An Emerging Theology in World Perspective. New York: TwentyThird Publications, 1988.

Libanio, João Batista. "Panorama da teología da América Latina nos últimos 20 anos”, Perspectiva Teológica, 24/ 63, (mayo-agosto de 1992).

McKeever, Martin. "Thirty years of liberation theology”, Theology Digest, 51, 2004.

Palti, Elías. "Roberto Schwarz y el problema de "las ideas fuera de lugar" Aclaraciones necesarias y contradicciones cuarenta años después", Avatares filosóficos, 1, Buenos Aires, 2014.

Park, Chung-Shin. Protestantism and politics in Korea. Seattle: University Washington Press, 2003. 
Park, Sung A. "Minjung Theology: A Korean Contextual Theology”, The Indian Journal of Theology, 33 (octubre-diciembre de 1984).

Park, Ro-hun. "The Emergence and Convergence of Christian Identities: An East Asian Reflection on the Bible, Minjung, and Identities", Revista Madang, 16 (diciembre de 2011).

Pattery, George. "Culture, Faith and Liberation”. Indian Journal of Theology, 36/ 2 (1994).

Pieris, Aloysius. An Asian Theology of Liberation. New York: Orbis, 1988.

Pieris, Aloysius. El rostro asiático de Cristo. Notas para una teología asiática de la liberación. Salamanca: Sígueme, 1991.

Premawardhana, Devaka. "The unremarkable hybrid: A. Pieris and the redundancy of multiplereligius belonging", Journal of Ecumenical Studies, 46/1 (Winter 2011).

Rao, Chilkuri Vasantha. "Dalit Christians Struggle for Justice in the Indian Subcontinent", Madang, 16 (December 2011: 35-54).

Ro, Bong-Rin (s/f) “Theological trends in Asia”. Disponible en: http://s3.amazonaws. com/tgc-documents/journal-issues/13.2_Ro.pdf.

Richard, Pablo. "La Iglesia y la Teología de la Liberación en América Latina y el Caribe: 1962-2002”, Pasos, 103 (septiembre-octubre de 2002).

Sánchez-Rivera Peiró, Juan M. "Introducción” a Pieris, Aloysius (1991). El rostro asiático de Cristo. Notas para una teología asiática de la liberación. Salamanca: Sígueme, 1991.

Silva, Sergio. La Teología de la Liberación”, Revista Teología y Vida, Vol. L., 2009.

Sobrino, Jon. "El conocimiento teológico en la teología europea y latinoamericana". Liberación y cautiverio: Debates en torno al método de la teología en América Latina, México, 1975.

Schoof, Mark. Breakthrough: The Beginnings of the New Catholic Theoloy. Dublin: Gilland Macmillan, 1970. 
Schwarz, Roberto. "As ideias fora do lugar" en Ao vencedor as batatas. Forma literária e processo social nos inicios do romance brasileiro, Livraria Duas Cidades, San Pablo, 2000.

Song, C.S. Third Eye Theology. Londres: Lutterworth Press, 1980.

Subercaseaux, Bernardo. "Reproducción y apropiación: dos modelos para enfocar el diálogo intercultural", Revista Estudios Públicos, 23, 1988.

Suh Nam-Dong. "Toward a Theology of Han" en Minjung Theology. People as the subject of history. Singapur: CCA-CTC, 1981. 